\title{
PREPARATION NEEDS OF INFERTILE COUPLES WHO SEEK TO ADOPT
}

\author{
KERRY DALY \\ University of Guelph
}

\begin{abstract}
Based on in-depth interviews with 74 infertile couples seeking to adopt children, suggestions are made for modifying public adoption practice. Key findings in the study suggest couples experienced a loss of control, felt inadequately prepared for adoptive parenthood, and were socially isolated. Suggestions are made for how to incorporate empowerment, education, and support into adoption practice in order to build a stronger foundation for adoptive relationships.
\end{abstract}

\section{INTRODUCTION}

The preparation needs of infertile couples who seek to adopt can best be understood against the backdrop of the current adoption situation in Canada. Two issues are significant. First, there is a worsening imbalance between the availability and demand for adoptable infants. Specifically, there is clear evidence which suggests that the availability of adoptable infants is rapidly diminishing (Bachrach, 1983, 1986; Bonham, 1977; Hepworth, 1980), while at the same time, there is evidence of a marginal increase in the number of couples who experience infertility (Aral \& Cates, 1983; Link \& Darling, 1986; Menning, 1977). This imbalance has created a tension in the public adoption system. The infertile couples who seek to adopt must contend with a long wait and in some cases, the possibility of not adopting at all. The adoption worker, on the other hand, must contend with the strain of being unable to place babies in the face of such a high demand.

Second, adoption practice in North America is rooted in a tradition of child welfare. In this regard, most public adoption agencies are mandated to place the needs of the adoptable child in the forefront. Although many agencies have policies which suggest that the home study for prospective adoptive couples should contain both evaluation and education (see, for example, Ministry of Community and Social Services, Ontario, 1979), it would appear that evaluation takes precedence when the needs of the child are a priority. Although education has not been overlooked in the adoption process, couples perceive that it is overshadowed by the evaluation procedure. The result is that prospective adoptive couples feel they are inadequately prepared for adoption. Adoption workers, on the other hand, face the impossible task of providing education along with assessment, when, in fact, they may be incompatible services.

These characteristics of adoption practice have an adverse effect, not only on

\footnotetext{
Requests for reprints should be sent to: Kerry Daly. Ph.D., Assistant Professor, Department of Family Studies, University of Gueiph, Guelph, ON N1G 2W1.
} 
the individual needs of the couple and the adoption worker, but they impose an escalating strain on the working relationship between adoption workers and their clients. In fact, the parallel frustrations of couples and the adoption workers may, in some instances, result in an adversarial or distrustful relationship.

In recognition that the current structure of adoption practice may create strain in this way, this paper makes suggestions for modifying the adoption process. The primary goal in suggesting these modifications is to better prepare couples for adoptive parenthood, and in so doing, create a better environment for the adoptee. Although this shifts the traditional child-welfare focus from the adoptee to the prospective adoptive parents, I would argue that this is consistent with the child-welfare philosophy: to invest in better preparation for the prospective adoptive couple is to invest in a better environment for the child. Second, these changes have the potential to alleviate some of the job strain experienced by the adoption worker who must work with incompatible expectations of providing both education and evaluation. Furthermore, by addressing these issues, some of the tension that exists in the professional relationship between adoption worker and client may be diffused.

It must be pointed out, however, that the starting point for the paper is the perceptions and expressed needs of the couples themselves. In this light, there is a bias in the orientation of the paper insofar as it approaches the issues from the couple's, and not the adoption worker's, experience. As a result, the primary emphasis is on the preparation needs of the prospective adoptive couple. However, in recognition that the adoption practitioner also encounters limitations in trying to meet these needs, the implications for the adoption worker's role will be examined by suggesting changes in the adoption process itself.

\section{METHOD}

This research followed the principles of grounded theory (Glaser \& Strauss, 1967). There were two phases in carrying out the research. The first phase involved participant observation at five infertility support-group meetings and unstructured, taped interviews with five infertile couples. The objective of this phase was to get sensitized to the salient issues and to generate substantive themes and categories that could be more systematically analyzed in the second phase. In the second phase, a structured interview schedule was established on the basis of the categories identified in phase one. Examples of these categories are: commitment to parenthood, salience of motherhood versus fatherhood, infertility as problematic, the response of significant others, critical incidents in the preparation for adoption, and perceptions of the formal adoption procedure. The objective of this phase of the research was to generate a more structured data set that would allow for a mix of qualitative and quantitative analysis.

Seventy-four couples were interviewed in phase two. This paper focusses on the data collected in these interviews. In order to be included in the study, couples had to be experiencing a fertility problem and have no children (biological or adopted) living with them. Couples were recruited through a fertility clinic at a large urban teaching hospital and through the adoption waiting lists at two Ontario Children's Aid Societies. Couples were deliberately reeruited from these different sources in order to ensure that there were couples at various stages in 
their consideraton of adoption. For example, many of the couples recruited from the fertility clinic had considered adoption as an option but had not taken concrete steps toward it, whereas all couples recruited through the adoption agencies were actively pursuing adoption.

Different approaches were used to contact couples in the two organizations. At the fertility clinic, patients were asked by the physician or nurse whether they would be willing to consider participating, and if so, they were immediately introduced to the researcher. The study was explained to them and if they were willing to participate, a time for an interview in their home was arranged. Among those who met the eligibility criteria at the fertility clinic, $71 \%$ agreed to an interview. In contrast to this face-to-face recruitment approach, adoption agencies sent out letters, on behalf of the researcher, to all people on their waiting lists. If couples were willing to participate, they responded directly to the researcher. This resulted in much lower participation rates with $42 \%$ responding from the first agency ( 107 letters sent) and $15 \%$ responding from the second agency ( 58 letters sent). The overall participation rate, including the fertility clinic and adoption agencies, was $43 \%$. One researcher did all the interviews and the analysis. The interviews ranged in length from one to four hours with most being $21 / 2$ hours long.

Both husband and wife were present in all interviews. This was done in recognition of the fact that husbands and wives have separate subjective realities that makes data collected from only one spouse unreliable when generalizing to the couples (Saffilios-Rothschild, 1969). Interviewing spouses together was also advantageous insofar as spouses jogged one another's memories and were able to corroborate statements made by each other which can serve to improve the reliability of their comments. Furthermore, men have typically been difficult to recruit for studies on private family topics such as this, and wives were often a welcome ally in encouraging husbands to participate.

The mean age of the sample was 31 for husbands and 30 for wives. Couples had experienced a fertility problem for a mean average of five years. Although all couples had given some consideration to adoption, three-fifths were formally on an adoption waiting list. Of these, one quarter had a completed home study and were awaiting placement.

\section{FINDINGS AND IMPLICATIONS}

Emerging from the data of the interviews are several key findings that will be discussed in order to make suggestions for how the adoption process might be modified, Three problematic issues which have implications for adoption practice have been identified: perceptions of a power imbalance; perceptions of inadequate preparation; and finally, social isolation. With each of these issues, the research finding that gives rise to the issue will be discussed, and second, ways that adoption practice might be reshaped in order to better meet the needs of prospective adoptive couples and adoption workers will be explored.

\section{Perceptions of Power Imbalance in the Adoption Process}

Finding: Loss of control. One of the most significant characteristics of couples who were experiencing infertility and seeking to adopt was a sense of having lost 
control over a fundamental and important dimension of their lives. Having been socialized to expect that they would settle down, get married and have children, the experience of a fertility problem cast their carefully articulated plans for parenthood into disarray. Not only were they faced with the possibility of a delay in the timing of the transition to parenthood, but they were faced with the prospect of not becoming parents at all.

Most couples indicated that having a fertility problem had reduced their sense of control over their lives, although wives were more likely to indicate this. Whereas only one-half of husbands indicated they felt less in control, more than three-quarters of wives indicated this. This gender difference is no doubt related to the greater salience of the parenthood role for women than for men. Whereas only seven percent of husbands and five percent of wives said parenthood was more important for the man, $54 \%$ of husbands and $60 \%$ of wives indicated it was more important for the woman. Other researchers (Bierkens, 1975; Brennan, 1977; Humphrey, 1977; Van Keep \& Schmidt-Elmendorff, 1975; Veevers, 1980) concur with the greater importance of parenthood for women.

There were several dimensions to this loss of control. At the most basic level, the loss of control associated with infertility was expressed through a sense of alienation from one's own body. As one woman pointed out, the body no longer complied with the choices she had made:

For me there has been a loss of control. It is no longer my choice as to whether or not I can get pregnant. People 1 know come off the pill and they get pregnant-that makes me mad. I just don't have control over my body.

As a result of being unable to control one's own body, there was a tendency to turn to physicians in order to regain a sense of control. Contrary to expectation, however, the loss of control that couples experienced was typically compounded in the medical process of tests and treatments. Couples became dependent on their physicians for a solution to their fertility problem. Doctors were perceived as holding the control over whether or not they would become parents. The dependence on doctors was reflected in one woman's comment that "the doctor is the main player, he is everything!"

The loss of control that couples experienced in the infertility process continued on and was exacerbated in the adoption process. Already having experienced a loss of control over having their own biological children, couples were now faced with the additional task of having to wait for, and depend on others, in order to become adoptive parents. The adoption agency was perceived to be very powerful by virtue of its position as determinant of whether or not the couple could become adoptive parents. As one woman described her feelings about the adoption process:

It has opened my eyes to the frustration of going through the process. You are at their beck and call when they decide that a match is made. You have no control. You have to submit yourself to the process.

The loss of control that couples experienced ranged from a personal loss of control over their own bodies to the interpersonal dependency and powerlessness they experienced in relation to their physicians and adoption workers.

Implication for practice: Empowerment of couples. The loss of control that couples experienced over the transition to parenthood resulted in feelings of 
anger, disillusionment, and stagnation. There is a need to empower couples to regain a sense of autonomy and control over this important crisis in their lives.

Although most couples had experienced a loss of control in their lives, few had publicly acknowledged it. Identifying and acknowledging the loss of control and the feelings associated with it would seem to be an important first step in correcting the power imbalance. As a next step, however, it would seem important that physicians and adoption workers reflect to couples the power that is attributed to them. In other words, rather than accepting that couples are dependent on them either for a cure or an adoptable infant, there is a need to minimize or reject this attribution of power.

For the medical practitioner, this may involve a recognition that there are limits to what reproductive medicine can do to correct the problem. The recognition by the doctor of limitations is significant insofar as it should serve to put a check on the investment, and therefore dependence, that couples have on their physician for a "cure." Although couples may not want to hear that their physician does not have the power to correct the problem, it may be functional insofar as it decreases the power that the physician is perceived to hold. As one woman pointed out:

There isn't anything you can do about infertility. It's up to the doctors. Even then, our doctor did all the tests and in the end, told us it was bad luck! At first, I looked at my husband and said, "Can you believe he said that?" But after a while, 1 started to admire him for saying that. There's nothing they can find, so it's just bad luck. Not even he can control it.

For the adoption worker, there is a need to disclaim the power that couples perceive them to hold. Although adoption workers make assessments and decisions about who gets babies, they may not have the high level of power that is attributed to them. This needs to be conveyed to couples in order to diffuse unrealistic expectations, and more importantly, to rightfully restore the locus of control with the couple themselves. Several points could be made to convey this to couples. First, in light of the acute shortage of adoptable babies, they have no power to provide babies. Second, few couples are ever rejected for adoptive parenthood. Third, although it may appear that there is considerable latitude in making decisions about who should adopt, there are specific criteria that must be followed in making assessments. In so doing, not only do adoption workers reject the power with which they are attributed, but they reflect it back to the couples who must then make their own decisions in the adoption process.

Releated to this, it would also appear that couples could regain a sense of control by being made aware of and exploring options to public adoption. For example, information on childlessness and private adoption would give couples more choice, and in the process, more autonomy.

\section{Perceptions of Inadequate Preparation for Adoption}

Findings: Abrupt transition to adoption and misleading images of adoption. Two issues emerged which suggested that couples were not well prepared to take on some of the unique contingencies of adoptive parenthood. First, there was a Prevailing concern expressed by couples that with adoption, there was no time to get ready for the parenting experience. Second, media presentations of adoption 
had a significant impact on couples but contained numerous inaccuracies and falsehoods about adoptive relationships and adoption law. As a result, their expectations for what would happen when they became adoptive parents may have been based on faulty or misleading information.

Most couples did not see the formal adoption process as helping them to prepare for adoption. When couples were asked how the agency had affected their feelings about adoption, $54 \%$ of husbands and wives reported they were being discouraged or judged by the agency. Their perception that adoption workers were there to assess them rather than to help them prepare, was reflected in the language they used to describe them: they felt they were being "judged," " interrogated," "on trial," "fine-combed," or that "someone was going to play God with us."

By contrast, only $15 \%$ indicated that the agency helped them to know what to expect with adoption. Unlike having a biological child where there is a ninemonth period to get ready for parenthood, the preparation for adoptive parenthood was perceived as occurring between the call from the agency that there was a baby and the actual arrival of the baby. This was usually only a period of two or three days and was seen as the time when all the preparations take place. In this respect, going through the long process of home studies and interviews with the agency tended not to be seen as preparation experience. One couple comments on the abruptness of the adoption process:

Husband: You're thrust into a new situation where you have to adapt. You don't have the nine months adjustment period. The actual adjustment occurs when the baby arrives.

Wife: You are thrown into it cold turkey. You don't have time to prepare yourself at all.

The abruptness with which adoption occurs was seen to create problems in bonding with the child, in psychologically feeling like a parent, and finally, in being able to quickly accommodate the parenthood role in light of other role commitments.

Media presentations of adoption also created problems in the preparation for adoptive parenthood. Couples typically reported that adoptive parenthood was portrayed in a negative light. Specifically, the popular press tended to focus on and glamorize cases of successful search where the adoptee finds and reunites with a birth parent. Similarly, popular television dramatizations tended to focus on the unstable aspects of adoptive relationships. A frequently mentioned theme in these programs was the search and happy reunion with birth parents, or quest on the part of a birth mother to regain custody of her child who was relinquished for adoption. As one woman succinctly described it, "ton TV, adoptees are always stepped on and they always seek their birth parents." These programs, although often conveying false information about the birth mother's legal access to the child, tended to make couples more apprehensive about adoption for fear that the child would be snatched away by the biological mother.

Both the perceived abruptness of adoption and the negative media portrayals interfered with a positive and realistic preparation for adoptive parenthood.

Implication for practice: Preparation through education. In light of the feelings of alienation from the agency and the negative media imagery, it would seem there 
is a strong need for couples to receive education and accurate information in order to prepare themselves for the adoption experience.

In order for education to be effective within the adoption process, it is necessary to disassociate it from the evaluation procedure. Since most agencies provide information about adoption as part of the home-study process, it tends to be seen as part of the "test" for whether or not they are "good enough" to become adoptive parents. For example, home-study interviews might include a question about the best time to tell an adoptee about adoption. Within the context of evaluation, couples may search for the "right" answer. However, if this kind of issue were raised within an educational context, the couple would be free to explore the different ways a parent could respond to the child without being afraid of giving a "wrong" answer that they feel could be "used against them."

In practical terms, separating education from evaluation means having separate individuals who are in charge of the home study and the educational program. Preferably, this educational task would be contracted to someone with no affiliation to the agency. Otherwise, the threat of evaluation might constrict the learning environment.

Additionally, in light of a wait of several years for an adoption placement to occur, it would make sense to initiate the education experience at an earlier point in the adoption process. Whereas most home studies occur near the end of several years of waiting, education might start closer to the beginning of the adoption process. This would give couples a better understanding of some of the unique challenges of becoming adoptive parents, and in so doing, put the waiting time to more constructive use.

Given that media portrayals often cast adoption in a negative light, and in some cases reinforce myths about adoption, there is an added urgency to provide accurate information to couples about the adoption experience. In addition to having an educator provide information, it would make sense to give an information package to couples when they apply that would include factual information about adoption rights and laws as well as "normalizing" information about the experiences of other couples who have gone through the process. Included in this would be information about when to tell and how to tell adoptees about adoption; and how to manage adoption as a stigma in relation to friends and family.

Separating education and evaluation would also have the effect of making the adoption experience more authentic for both couples and adoption workers. Because of the perception they were being evaluated, there was a tendency toward "impression management" (Goffman, 1959). In order to receive approval for adoptive parenthood, couples adopted the deliberate strategy of proving to the agency representatives they would be the " $100 \%$ best human being possible to be I" parent." Rather than using the adoption process as an opportunity to work through their feelings about infertility and adoption, the over-riding concern was to "tell them what they wanted to hear," "be accommodating for them," or at very least, be careful not to say anything incriminating.

An educational experience that was separate from the evaluation procedure Would no doubt provide for couples a more authentic context for the expression of their needs and concerns. Furthermore, separating these two functions would make the adoption worker's job more focussed and less strained, because they 
would not have to try to provide support and education through the "perfectparent" facade.

\section{Support}

Finding: Social isolation. Failure to become parents when they were expected to do so created for most couples a generalized feeling of being left behind or set apart from their peers. Eighty-four percent of couples expressed in some way that they felt a pressure from others to become parents. One couple described how infertility and the plan to adopt cast them as outsiders to the normal course of development:
Wife: You don't feel like you are part of the mainstream. Even watching TV the emphasis is on having kids. It is even difficult to make friends because they expect you to have children.
Husband: It makes you very sensitive that the whole world is geared towards the nuclear family.
Wife: It's like a membership. You aren't part of the group when you have a fertility problem. Our friends who have had children seem to apologize for them.

Witnessing family members and friends get pregnant and have children also focused attention on the absence of the parenthood role. These relationships often became strained as a result of the ease with which these others could get pregnant and have children.

Couples reported that others who did not experience a fertility problem or have experience with adoption would have difficulty in understanding their predicament. As one woman put it:

People who don't have the problem just can't understand. Like it's just natural to have kids and people put so much energy into not getting pregnant.

To take fertility pills, people think you are crazy!

From those who did share the problem and could therefore share in the definition of the situation, there emerged a sense of comfort from feeling less isolated:

Because I know others I don't feel so isolated. It's nice to see that others are going through it as well. I feel more comfortable knowing I'm not the only one going through $\mathrm{it}$. Secing others and their experiences and secing that their feelings are the same is comforting.

As these findings would suggest, the experience of a fertility problem was isolating insofar as it set these couples apart from their peers who became biological parents as expected.

Implications for practice: Social support. Providing social support for infertile couples who seek to adopt can take many forms. Two mechanisms, however, seem appropriate and possible as part of the adoption process: one a professional I client model, the other a peer support model.

Most agencies provide some level of professional support to couples. This typically occurs through phone contacts or within the context of the home study. Discussions about childlessness, infertility, and feelings about adoption provide an opportunity for adoption workers to provide support and to normalize the feelings couples may have. Some agencies provide, and in some instances require, 
participation in a group that is run by one of the adoption workers. This, too, provides an important opportunity for couples to overcome their feelings of isolation. However, although these opportunities within the formal adoption process play an important role in providing support for couples, they are limited by the invasiveness of the evaluation procedure.

The peer-support model may provide the best opportunity for couples to work through their feelings of frustration and isolation without having to be concerned that what they say may be incriminating. In the absence of the adoption worker, couples might feel freer to express concerns, anxieties, and reservations about the adoption process that might not otherwise surface.

Here the adoption professional could play a facilitating role in getting the group going and supporting its continued functioning. At the outset, this would involve identifying and encouraging several couples to play a leadership role in running such a group. The adoption worker would also arrange for, or offer to be, a professional advisor to the group. Furthermore, the adoption worker could play an important role in facilitating the provision of other resources that are required to run such a group, such as providing a room, photocopying facilities, mailing support and secretarial services.

Allowing couples the safe context of a support group is no doubt an important part of the preparation for adoptive parenthood. It provides an opportunity to come to terms with their feelings of loss associated with infertility, to feel less alone in their feelings about infertility and adoption, and to have the opportunity to support others who are having the same experience. Having thus had the opportunity to work through some of these issues, they are no doubt in a healthier position to assume the responsibilities of adoptive parenthood.

\section{CONCLUSION}

The perceptions of prospective adoptive couples that there is an imbalance of power in the adoption process, that the transition occurs abruptly with little preparation, and that it is an isolating experience, are the grounds for suggesting modifications in adoption practice. These modifications include giving back to couples a sense of control, providing the opportunity for information and education about adoption, and finally, facilitating social support in order to assist them through this crisis. By reshaping adoption practice in this way to meet these needs, couples will arrive at adoptive parenthood better equipped to meet the challenges of the adoption experience.

In addition, it would seem that such modifications would pay dividends for adoption workers. Although on the surface, they may appear to add work, they have the potential to alleviate some fundamental stresses that exist in the adoption process by virtue of the current structure. Incompatible expectations of education and evaluation, the burden of power arising from the assessment procedure and the difficult task of dealing with couples' impression-management strategies could be significantly reduced through such changes. Not only would this alleviate some of the strain that is presently inherent in the job, but it would also have the potential to make for a more trusting and authentic relationship between the adoption worker and the prospective adoptive couple. 
The needs for empowerment, education, and support have been identified in this paper as central needs. However, a discussion of these preparation needs would not be complete without some attention given to some of the obstacles that might get in the way of their implementation. Lack of resources is no doubt the major obstacle. One consideration here would be to have couples pay a small fee for some services. Not only would this help to reduce the drain on resources but it might increase the couples' commitment to the process. Limited time on the part of the adoption worker or lack of access to outside professionals who might play a facilitating or educational role with couples could block such programs. Professionals in public health or other family services are a pool of people who might be called on to act out such a role. Another obstacle might include resistance from couples themselves who may see infertility and adoption as private isstes. Although all couples would no doubt benefit from educational and supportive services, none should be required to participate in them.

\title{
RESUME
}

\begin{abstract}
A la suite d'entrevues en profondeur auprès de 74 couples infertiles désireux d'adopter des enfants, on fait des suggestions pour modifier la pratique de l'adoption publique. On a principalement découvert que les couples font l'expérience de la perte de contrôle, se sentent mal préparés à devenir parents adoptifs, et sont socialement tsolés. Pour consolider les bases de la relation d'adoption, il est suggéré d'intégrer aux pratiques d'adoption un plus grand contrôle, l'éducation et le support.
\end{abstract}

\section{REFERENCES}

Aral, S.O., \& Cates, W. (1983). The increasing concern with infertility, Why now? Journal of the American Medical Association, 250, 2327-2331.

Bachrach, C.A. (1983). Adoption as a means of family formation: Data from the national survey of family growth, Journal of Marriage and the Family, 45, 859-865.

Bachrach, C.A. (1986). Adopted plans, adopted children and adoptive mothers, Journal of Marriage and the Family, 48, 243-254.

Bierkens, B.P. (1975). Childlessness from a psychological point of view. Bulletin of the Menninger Clinic, 39, 177-182.

Bonham, G.S. (1977). Who adopts: The relationship of adoption and social demographic characteristics of women. Journal of Marriage and the Family, 39, 295-306.

Brennan, W.C. (1977). An investigation of psychological symptom distress levels of childless couples choosing adoption (Doctoral dissertation, The State University of New Jersey). Dissertation Abstracts International, 37, 6315.

Bresnick, E.R. (1981). A holistic approach to the treatment of the crisis of infertility. Journal of Marriage and Family Therapy, 7, 181-188.

Daly, K.J. (1988). Reshaped parenthood identity: The transition to adoptive parenthood. Journal of Contemporary Ethnography, 17, 40-66.

Glaser, B., \& Strauss, A. (1967). The discovery of grounded theory: Strategies for qualitative research. New York: Aldine.

Goffman, E. (1959). The presentation of self in everyday life. New York: Doubleday.

Hepworth, H.P. (1980), Foster care and adoption in Canada, Ottawa: Canadian Council on Social Development.

Humphrey, M. (1977). Sex differences in attitudes to parenthood. Human Relations. $30,737-750$. 
Link, P.W., \& Darling, C.A. (1986). Couples undergoing treatment for infertility: Dimensions of life satisfaction, Journal of Sex and Marital Therapy, 12, 46-59.

Menning, B.E. (1975). The infertile couple: A plea for advocacy. Child Welfare, 56, $454-460$.

Menning, B.E. (1977), Infertility: A guide for the childless couple, Englewood Cliffs, NJ: Prentice-Hall.

Menning, B.E. (1980), The emotional needs of infertile couples. Fertility and Sterility, 34, 313-319.

Ministry of Community and Social Services (Ontario). (1979). The person other than the agency. Toronto: Author.

Saffilios-Rothschild, C. (1969). Family sociology or wive's family sociology? Joumal of Marriage and the Family, 31, 290-301.

Van Keep, P.A., \& Schmidt-Elmendorff, H. (1975). Involuntary childlessness. Journal of Biosocial Science, 7, 37-48.

Veevers, J.E. (1980). Childless by choice. Toronto: Butterworth5. 